07

\title{
Экспериментальное обнаружение резонансного туннелирования \\ в легированной структуре \\ с одиночной квантовой ямой методом адмиттансной спектроскопии
}

\author{
() Я.В. Иванова, В.И. Зубков, А.В. Соломонов
}

Санкт-Петербургский государственный электротехнический университет „ЛЭТИ“, Санкт-Петербург, Россия

E-mail: ivanova@unix-server.su

Поступило в Редакцию 14 июня 2018 г.

Проведены адмиттансные измерения серии гетероструктур с прецизионно выращенными методом MOCVD квантовыми ямами (КЯ) $\operatorname{In}_{x} \mathrm{Ga}_{1-x} \mathrm{As} / \mathrm{GaAs}$ $(0.19 \leq x \leq 0.3)$. Впервые методом адмиттансной спектроскопии зарегистрировано наличие резонансно-туннельной эмиссии как определяющего механизма формирования высокочастотной проводимости легированных гетероструктур с КЯ, проведено разделение туннельного и резонансно-туннельного вкладов и проанализировано влияние туннельной составляющей на общий темп эмиссии носителей из КЯ. Выполнено самосогласованное моделирование вольтфарадных характеристик структур, а также расчет коэффициента прозрачности системы, формируемой потенциалом Хартри в окрестности КЯ. Экспериментально и путем численных расчетов показано, что вероятность резонанснотуннельной эмиссии падает с ростом обратного смещения из-за нарушения симметричности барьеров.

DOI: 10.21883/PJTF.2018.24.47038.17426

К настоящему времени теоретически проанализировано и экспериментально подтверждено множество проявлений квантово-механических эффектов в наноструктурах. Одним из наиболее интересных и перспективных для приборных приложений является резонансное туннелирование. С момента его открытия [1-3] резонансное туннелирование как особый вид туннельного эффекта исследовалось различными экспериментальными методами, а измерения, как правило, выполнялись на специально изготовленных двух- или многобарьерных структурах. 
Традиционно весьма информативными методами наблюдения туннельного транспорта носителей заряда являются оптические. Например, в [4] методами фотолюминесценции и фототока было показано, что туннелирование носителей из хвостов плотности состояний активного слоя InGaN в зоны в квантовых ямах (КЯ) InGaN/GaN дает ощутимый вклад в падение квантового выхода светодиодов с ростом тока. В [5] исследовалось влияние надбарьерного туннелирования на положение уровней размерного квантования в системе с двумя симметричными КЯ InGaAs/GaAs.

Из экспериментальных исследований электрическими методами отметим, например, работу [6], в которой обнаружены области отрицательной дифференциальной проводимости в сильно связанных сверхрешетках $\mathrm{GaAs} / \mathrm{AlGaAs}$, возникающие вследствие наличия резонансных эффектов, обусловленных межминизонным туннелированием.

Что касается адмиттансных методов, то в работе [7] методом DLTS (deep-level transient spectroscopy) исследовалось туннелирование носителей заряда в структуре с одиночным барьером $\mathrm{AlGaAs}$ и было показано его влияние на результаты определения величины разрыва зон. В $[8,9]$ анализировалось уменьшение определяемой в эксперименте энергии активации при эмиссии из множественных КЯ за счет туннельного эффекта. При этом в указанных и других подобных публикациях, как правило, оставалось невыясненным, где имеет место обычное туннелирование, а где резонансное.

В настоящей работе впервые методами адмиттансной спектроскопии зарегистрировано наличие резонансно-туннельного механизма эмиссии как определяющего в формировании высокочастотной проводимости легированных гетероструктур (ГС) с КЯ, проведено разделение туннельного и резонансно-туннельного вкладов и проанализировано влияние туннельной составляющей на общий темп эмиссии носителей заряда из одиночной КЯ. Выполнено самосогласованное моделирование вольтфарадных характеристик структур, а также расчет коэффициента прозрачности системы, формируемой потенциалом Хартри в окрестности одиночной КЯ с легированными обкладками.

Исследовалась серия образцов $\Gamma \mathrm{C} \operatorname{In}_{x} \mathrm{Ga}_{1-x} \mathrm{As} / \mathrm{GaAs}$ с составом КЯ по In от $x=0.19$ до 0.3 , выращенных методом MOCVD (metalorganic chemical vapour deposition). Дизайн образцов был оптимизирован для проведения емкостных измерений [10]. Уровень легирования подложки составлял $10^{18} \mathrm{~cm}^{-3}$. Толщина КЯ была равна $6.0-9.5 \mathrm{~nm}$. Квантовая

8 Письма в ЖТФ, 2018, том 44, вып. 24 
яма вместе со спейсерными слоями $i$-GaAs толщиной $5 \mathrm{~nm}$ находилась между двух слоев $\mathrm{GaAs}$ шириной соответственно $300 \mathrm{~nm}$ (кэп-слой) и $350 \mathrm{~nm}$ (нижний слой), равномерно легированных $\mathrm{Si}$ в процессе роста до $(6-7) \cdot 10^{16} \mathrm{~cm}^{-3}$. Точность параметров и качество структур контролировались методами рентгеновской дифракции высокого разрешения (HRXRD), локальной катодолюминесценции и др. [11], показавшими высокое совершенство гетерограниц. Однородное легирование барьерных областей обеспечивало высокую симметричность профиля потенциальной энергии вблизи КЯ.

C помощью RLC-метра Agilent E4980A измерялся комплекс адмиттансных характеристик ГС при воздействии на образец температуры, приложенного смещения и различной частоты тестового сигнала. Диапазон измерений температуры составлял от 10 до $375 \mathrm{~K}$, диапазон напряжений $\pm 40 \mathrm{~V}$, диапазон частот тестового сигнала $1 \mathrm{kHz}-2 \mathrm{MHz}$ [12].

При малом содержании индия в составе твердого раствора КЯ сигнал спектров проводимости не превышал уровня шумов измерительного оборудования. Во-первых, в этом случае энергия активации носителей заряда с уровней квантования КЯ невелика из-за малой величины разрыва зон, и термоактивационный пик будет возникать в области очень низких температур. Во-вторых, при малом содержании индия уровень квантования оказывается существенно выше уровня Ферми и концентрация в соответствующих подзонах КЯ резко падает даже при низких температурах. В-третьих, уровни квантования становятся более делокализованными $[13,14]$, что приводит к еще большему размытию пиков в наблюдаемых спектрах. Только для составов с содержанием In выше 0.23 в эксперименте наблюдался отклик высокочастотной проводимости с уверенным соотношением сигнал/шум (рис. 1, $a$ ).

Типичные спектры проводимости для образца с $x=0.29$ в характерных точках по напряжению приведены на рис. $1, b$. Они претерпевают кардинальную модификацию при изменении смещения. Пики в спектрах наиболее ярко выражены при обратном смещении $-2.3 \mathrm{~V}$, что соответствует началу интенсивного рассасывания заряда из КЯ проникающим в нее электрическим полем, которое вызывает термополевую эмиссию электронов с подзон квантования. Термоактивационный характер наблюдаемого процесса подтверждается температурным сдвигом максимума спектра проводимости $(G-T)$ от частоты измерений [11]. Анализ экспериментальных данных показывает, что термоактивационный пик регистрируется в узком диапазоне напряжений $-2.3 \pm 0.3 \mathrm{~V}$.

Письма в ЖТФ, 2018, том 44, вып. 24 

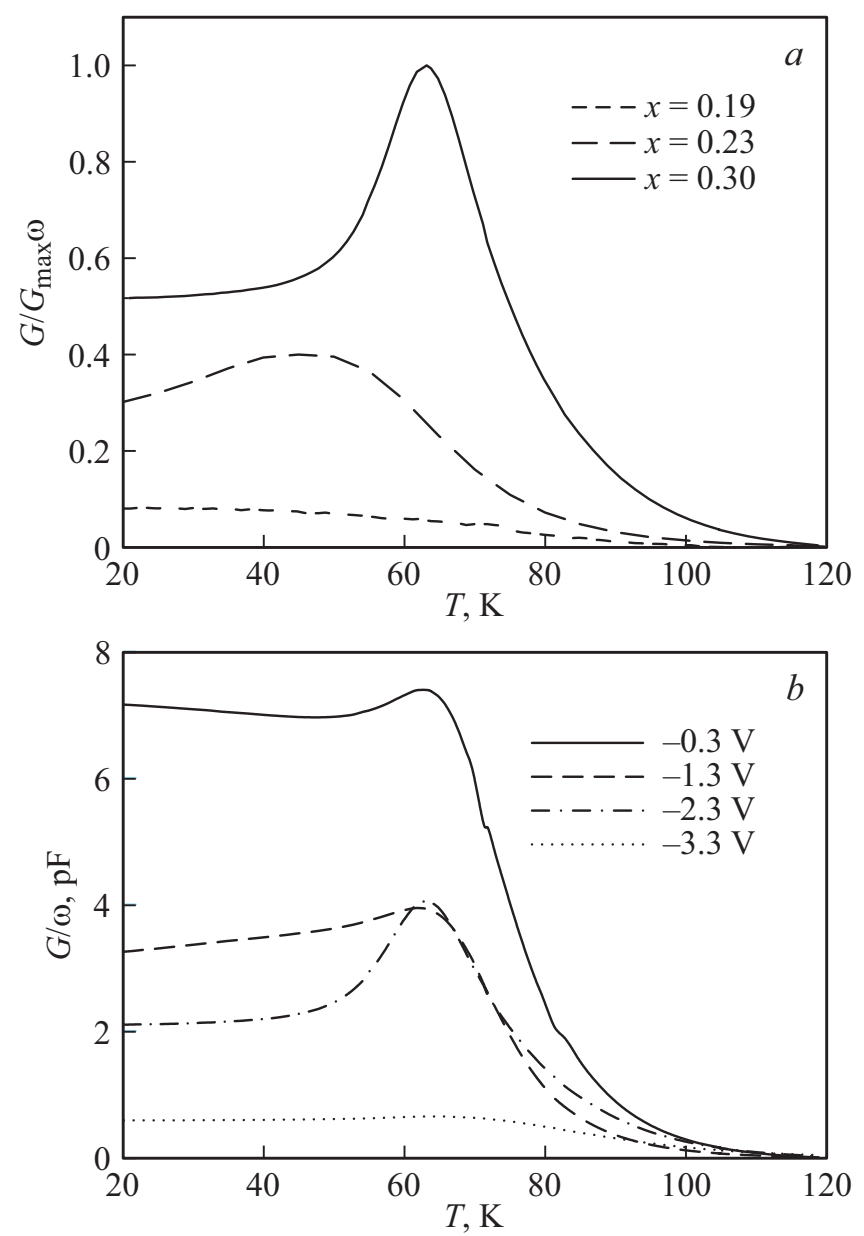

Рис. 1. Температурные спектры проводимости. $a$ - для серии образцов с одиночной КЯ $\operatorname{In}_{x} \mathrm{Ga}_{1-x} \mathrm{As} / \mathrm{GaAs}$ различного состава твердого раствора, $b$ - для образца с $x=0.29$ при различных обратных смещениях.

При температурах $20-50 \mathrm{~K}$ в спектрах проводимости наблюдаются горизонтальные „полки“. Как показано, например, в $[15,16]$, отсутствие температурной зависимости свидетельствует о туннельном механизме

$8^{*}$ Письма в ЖТФ, 2018, том 44, вып. 24 
эмиссии носителей заряда из КЯ. Наибольшее значение отклика проводимости наблюдается при минимальном смещении $-0.3 \mathrm{~V}$, при этом график практически параллелен оси температур. При дальнейшем росте обратного смещения до $-1.3 \mathrm{~V}$ горизонтальный участок испытывает резкий спад.

Полученные в серии экспериментов результаты анализировались нами с помощью численных расчетов электронного спектра ГС и коэффициента прозрачности образованной легированием двухбарьерной структуры с КЯ. Расчет энергетической диаграммы проводился путем самосогласованного решения уравнений Шредингера и Пуассона в квантовом ящике [10,12]. Разрыв зоны проводимости ГС с напряженной КЯ InGaAs/GaAs определялся подгонкой численного расчета вольтфарадных характеристик к экспериментальным данным. Энергетическая диаграмма легированной ГС с КЯ представлена на рис. 2, $a$. Для КЯ шириной $6.0 \mathrm{~nm}$ при $x=0.29$ разрыв зоны проводимости составил $220 \mathrm{meV}$. Расчет показывает наличие одного связанного уровня с $E_{1}=-55.3 \mathrm{meV}$ и одного квазирезонанса $E_{2}$ в области положительных энергий порядка $+80 \mathrm{meV}$.

На следующем этапе проводился расчет туннельной прозрачности $(T r)$ исследуемой структуры с одиночной КЯ. Для этого использовался метод численного решения внутренней задачи [17]. Систему двух потенциальных барьеров формировал самосогласованный потенциал Хартри из предыдущего расчета. Граничные условия для решения этой задачи совпадали с выбранными границами квантового ящика при решении уравнений Пуассона и Шредингера. Подробности алгоритма, реализованного нами на сетке из $10^{6}$ расчетных точек, приведены в [18]. Результаты расчета демонстрируют наличие резонанса в туннельной прозрачности при энергии, равной $+80 \mathrm{meV}$ (рис. 2, $b$ ). Увеличение обратного смещения модифицирует форму барьеров и вызывает падение резонансно-туннельной прозрачности вследствие нарушения симметричности потенциала.

Обратимся снова к спектрам проводимости на рис. $1, b$. При минимальном обратном смещении электрическое поле и область объемного заряда располагаются вдали от КЯ, поэтому она остается симметричной с идентичными по форме потенциальными барьерами (см. рис. 2,a). При этом „полки“ на температурных спектрах проводимости принимают максимальные значения. При таких смещениях в коэффициенте прозрачности наблюдается резонанс. Следовательно, большая величина 

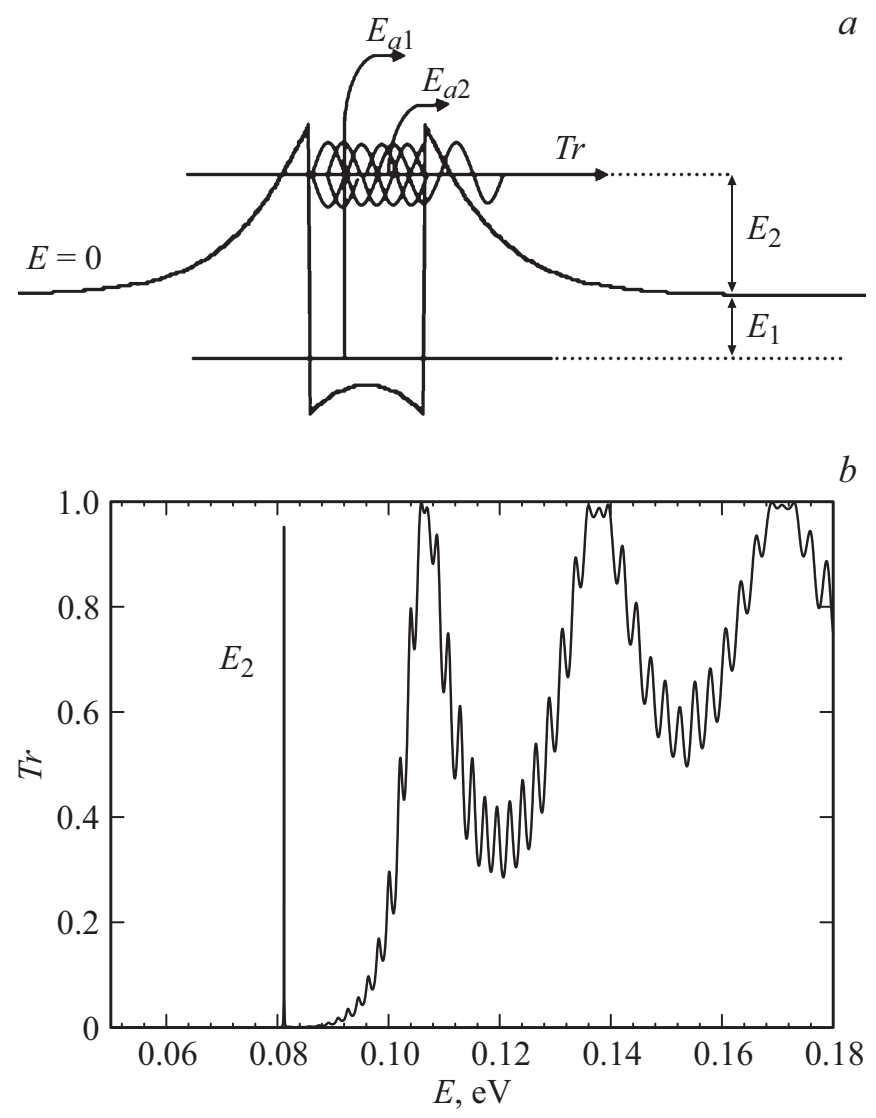

Рис. 2. Результаты моделирования. $a-$ самосогласованный потенциал Хартри с уровнями квантования в яме, $b-$ рассчитанный коэффициент прозрачности легированной ГС с одиночной КЯ при $x=0.3$ и обратном смещении $U=-0.3 \mathrm{~V}$.

проводимости при низких температурах и малых обратных смещениях обусловлена резонансным туннелированием, происходящим через квазирезонансный уровень.

По мере увеличения обратного смещения и расширения области объемного заряда левая сторона потенциального профиля КЯ начи-

Письма в ЖТФ, 2018, том 44, вып. 24 
нает приподниматься, симметрия барьеров нарушается, и резонанснотуннельная прозрачность системы падает. На экспериментальных спектрах это выражается в резком падении „полки“ начиная с $-1.3 \mathrm{~V}$. Расчет туннельной прозрачности при этом напряжении демонстрирует исчезновение резонанса. Составляющая, связанная с обычным туннелированием (проникновение волновой функции в подбарьерную область), присутствует всегда, но вклад ее значительно уступает резонансной и термополевой эмиссии.

Таким образом, в работе методом адмиттансной спектроскопии впервые экспериментально обнаружена и проанализирована резонансно-туннельная эмиссия носителей заряда из легированной ГС с одиночной КЯ InGaAs/GaAs. Показано, что определяющую роль в низкотемпературной эмиссии носителей заряда из КЯ при обратном смещении играет туннельная составляющая. Проведенное численное моделирование электронного спектра и коэффициента прозрачности позволило определить интервал смещений, в которых превалирует резонансно-туннельный механизм эмиссии.

Авторы благодарят M. Weyers и F. Bugge (Институт СВЧ-электроники Фердинанда Брауна, Берлин) за изготовление образцов.

\section{Список литературы}

[1] Chang L.L., Esaki L., Tsu R. // Appl. Phys. Lett. 1974. V. 24. P. 593-595.

[2] Esaki L., Chang L.L. // Phys. Rev. Lett. 1974. V. 33. P. 495- 498.

[3] Sollner T.C.L.G., Goodhue W.D., Tannenwald P.E., Parker C.D., Peck D.D. // Appl. Phys. Lett. 1983. V. 43. P. 588-590.

[4] Бочкарева Н.И., Вороненков В.В., Горбунов Р.И., Зубрилов А.С., Леликов Ю.С., Латышев Ф.Е., Ребане Ю.Т., Цюк А.И., Шретер Ю.Г. // ФТП. 2010. T. 44. B. 6. C. $822-828$.

[5] Орлов Л.К., Ивина Н.Л., Романов Ю.А., Рубцова Р.А. // ФТТ. 2000. Т. 42. B. 3. C. $537-541$.

[6] Андронов А.А., Додин Е.П., Зинченко Д.И., Ноздрин Ю.Н. // ФТП. 2013. T. 47. B. 1. C. $65-67$.

[7] Zhu Q.S., Mou S.M., Zhou X.C., Zhong Z.T. // Appl. Phys. Lett. 1993. V. 62. N 22. P. 2813-2814.

[8] Letartre X., Stievenard D., Lannoo M., Lippens D. // J. Appl. Phys. 1990. V. 68. N 1. P. $116-119$.

[9] Кучерова О.В., Зубков В.И., Соломонов А.В., Давыдов Д.В. // ФТП. 2010. T. 44. B. 3. C. $352-357$.

Письма в ЖТФ, 2018, том 44, вып. 24 
[10] Zubkov V.I., Melnik M.A., Solomonov A.V., Tsvelev E.O., Bugge F., Weyers M., Tränkle G. // Phys. Rev. B. 2004. V. 70. N 7. P. 75312.

[11] Зубков В.И. Диагностика полупроводниковых наногетероструктур методами спектроскопии адмиттанса. СПб.: Элмор, 2007. 220 с.

[12] Зубков В.И. // ФТП. 2007. Т. 41. В. 3. С. 331-337.

[13] Bimberg D., Grundmann M., Ledentsov N.N. Quantum dot heterostructures. John Wiley \& Sons, 1999. 333 p.

[14] Ким Ч.С., Сатанин А.М., Штенберг В.Б. // ФТП. 2002. Т. 36. В. 5. С. 569 575.

[15] Kapteyn C.M.A. Carrier emission and electronic properties of self-organized semiconductor quantum dots. Dissertation. Berlin: Mensch \& BuchVerlag, 2001. $156 \mathrm{p}$.

[16] Schmalz K., Rucker H., Yassievich I.N., Grimmeiss H.G. // Solid-State Electron. 1994. V. 37. P. 945-948.

[17] Сатанин А.M. Динамика электронов в наноструктурах. Н. Новгород: ННГУ, 2006. $96 \mathrm{c.}$

[18] Иванова Я.В., Зубков В.И. // Изв. СПбГЭТУ „ЛЭТИ“. 2018. № 5. С. 5-10.

Письма в ЖТФ, 2018, том 44, вып. 24 